\title{
'Mystery big cats' in the Peruvian Amazon: morphometrics solve a cryptozoological mystery
}

Two big cat skulls procured from hunters of Yanachaga National Park, Peru, were reported as those of cats informally dubbed the 'striped tiger' and 'anomalous jaguar'. Observations suggested that both skulls were distinct from those of jaguar, associated descriptions of integument did not conform to this species, and it has been implied that both represent members of one or two novel species. We sought to resolve the identity of the skulls using morphometrics. DNA could not be retrieved since both had been boiled as part of the defleshing process. We took 36 cranial and 13 mandibular measurements and added them to a database incorporating nearly 300 specimens of over 30 felid species. Linear discriminant analysis resolved both specimens as part of Panthera onca with high probabilities for cranial and mandibular datasets. Furthermore, the specimens exhibit characters typical of jaguars. If the descriptions of their patterning and pigmentation are accurate, we assume that both individuals were aberrant. 


\section{1 'Mystery big cats' in the Peruvian Amazon: morphometrics solve a}

\section{2 cryptozoological mystery}

4 Darren Naish $^{1 *}$, Manabu Sakamoto ${ }^{2}$, Peter Hocking ${ }^{3}$, Gustavo Sanchez ${ }^{4}$

$6{ }^{1}$ Ocean and Earth Science, National Oceanography Centre, Southampton, University of

7 Southampton, Southampton SO14 3ZH, UK, eotyrannus@gmail.com (corresponding author)

$8{ }^{2}$ School of Earth Sciences, University of Bristol, Bristol, BS8 1RJ, UK

$9{ }^{3}$ Natural History Museum of the University of San Marcus, Lima, Peru

$10{ }^{4}$ Fundación Neotrópico, La Laguna, 38208, Tenerife, Canary Islands, Spain

12 Keywords: Panthera, Felidae, jaguar, morphometrics, Peru

14 Abstract

16 Two big cat skulls procured from hunters of Yanachaga National Park, Peru, were reported as

17 those of cats informally dubbed the 'striped tiger' and 'anomalous jaguar'. Observations

18 suggested that both skulls were distinct from those of jaguar and associated descriptions of

19 integument did not conform to this species; it has hence been implied that both specimens

20 represent members of one or two novel species. We sought to resolve the identity of the skulls

21 using morphometrics. DNA could not be retrieved since both had been boiled as part of the

22 defleshing process. We took 36 cranial and 13 mandibular measurements and added them to a

23 database incorporating nearly 300 specimens of over 30 felid species. Linear discriminant

24 analysis resolved both specimens as part of Panthera onca with high probabilities for cranial and 
25 mandibular datasets. Furthermore, the specimens exhibit characters typical of jaguars. If the

26 descriptions of their patterning and pigmentation are accurate, we assume that both individuals

27 were aberrant.

29 Keywords: Panthera, Felidae, jaguar, morphometrics, Peru

31 Introduction

33 The continued existence of undiscovered, large $(>10 \mathrm{~kg})$, terrestrial mammal species in the extant

34 fauna is not beyond possibility, despite the expectation that all remaining undiscovered mammals

35 are predominantly small. Indeed, while it is popularly supposed that the inventory of large,

36 terrestrial species is mostly complete, several have been named within recent decades, including

37 the Saola Pseudoryx nghetinhensis (Van Dung et al., 1993), Dingiso Dendrolagus mbaiso

38 (Flannery et al., 2005), Giant or Large-antlered muntjac Muntiacus vuquangensis (Do Tuoc et al.,

39 1994), Small red brocket Mazama bororo (Duarte and Jorge, 1996), Giant peccary Pecari

40 maximus (van Roosmalen et al., 2007; Gongora et al., 2007) and Kabomani tapir Tapirus

41 kabomani (Cozzuol et al., 2013). Indeed, approximately 10\% of the 5000 extant mammal species

42 have been named since 1993 (Reed et al., 2007; Ceballos and Ehrlich 2009), though note that

43 approximately $60 \%$ are so-called cryptic species.

44 Of those large-bodied, terrestrial mammal species named recently, all inhabit tropical forests

45 in southeast Asia, South America and New Guinea. Some or most were known to local people

46 prior to scientific discovery. Furthermore, several were initially known from circumstantial data

47 collected by field researchers. Examples include the Kipunji Rungwecebus kipunji, discovered in

482006 following observations of a mystery monkey (Beckman 2005, Jones et al., 2005), and 
49 Burmese snub-nosed monkey Rhinopithecus strykeri, discovered in 2010 following investigation

50 of local reports about a "monkey with an upturned nose" (Geissmann et al., 2010).

51 In view of the possible existence of previously undocumented species of new, large terrestrial

52 mammal, and of the recognition of such species following investigation of ethnic knowledge, it is

53 worth taking seriously suggestions that new large mammal species might exist in such regions as

54 tropical South America.

55 Fieldwork in the Peruvian Amazon reveals that local people refer to several mammals that 56 potentially represent undiscovered taxa (Hocking, 1992, 1996). Two large cat skulls, identified by

57 local people as belonging to two of the region's 'mystery' cats, were procured during the 1990s

58 (Figs 1-2). Both had been defleshed and cleaned by boiling prior to being passed to one of us

$59(\mathrm{PH})$. In view of this we did not pursue the possibility of extracting DNA (though we recognize

60 the possibility that it still may be possible to extract some using specialized techniques).

61 One of these skulls - reported to belong to an animal known as the 'striped tiger' - was

62 obtained from a Pasco Province hunter who sold its skin to an unknown party (Fig. 1). The

63 'striped tiger' is allegedly a striped, jaguar-sized cat (Hocking, 1992). We use the less paradoxical

64 term 'Peruvian tiger' for this alleged animal. According to eyewitnesses, the body of this animal

65 is mostly reddish and patterned with white, unbranched stripes ( $\mathrm{PH}$, unpublished data). A second

66 distinctive big cat skull was obtained in 1993 from another hunter: it reportedly came from a

67 cinnamon-brown and white, leopard-like animal heavily marked with solid black spots (Fig. 2). It

68 was referred to in a previous report as an 'anomalous jaguar' (Hocking, 1996).

69 Large Amazonian cat skulls, conforming to Panthera and not to Puma, are assumed to be

70 those of jaguars. However, preliminary observations indicated that both skulls differed from those

71 of jaguars: the 'Peruvian tiger' skull appeared larger and differed in having a shorter, deeper face,

72 a more gracile zygomatic arch and, possibly, a shallower lower jaw. It also differed in

73 proportions: an indisputable jaguar skull exhibited a width : height ratio of 1.59 while the same 
74 ratio in the 'Peruvian tiger' is 1.37 (Bille, 1997). A convex frontal region appears reminiscent of

75 the same feature in tigers (P. tigris). The possibility that either or both Peruvian skull might

76 represent tigers is worthy of consideration since anecdotal tales report escaped tigers living in the

77 neotropics (Shuker, 1989). However, in addition to an elevated frontal region, P. tigris possesses

78 long nasals that project beyond the anterior extremities of the maxillae: the 'Peruvian tiger' lacks

79 these and appears comparatively short-faced.

80 We were interested in testing the possibility that either skull might represent a potential new

81 species and therefore subjected both to morphometric tests. High quality casts of the original

82 skulls were used for our study (see supplementary electronic material) (Figs 1-2).

\section{Materials and Methods}

Thirty-six cranial and thirteen mandibular measurements were taken (see supplementary

87 electronic material). Since the majority of variance in linear morphometrics reflects an individual's size, cranial and mandibular morphometrics were standardized through division by

89 the geometric means (GM) of each set (Mosimann, 1970). These measurements were compared to a pre-existing data set compiled by one of us (MS) as part of an integrative analysis of cranial

91 and mandibular morphological and functional evolution in Felidae (Sakamoto \& Ruta, 2012).

92 Linear discriminant analysis (LDA) was conducted on 33 felid species covering 290

93 specimens for cranial data, and 34 species covering 301 specimens for mandibular data using the

94 same 36 cranial and 13 mandibular standardized morphometrics (supplementary electronic

95 material). Cranial and mandibular datasets were analysed separately since not all specimens

96 overlap in the completeness of cranial and mandibular data (specimens with missing data were

97 excluded from the analyses so those lacking mandibular measurements would be eliminated in a 
combined dataset but retained in a cranial only dataset, thus preserving sufficient sample size).

99 Each specimen was given prior classification following recently published taxonomy (Werdelin 100 et al., 2010). The resulting discriminant functions from the training sets were used to predict the

101 classifications of the Peruvian specimens. Since the LDA is performed without the inclusion of

102 the Peruvian specimens, the resulting discriminant functions are unbiased by information from

103 the unknown specimens to be tested. LDA and predictions were performed using the MASS

104 library (Venables and Ripley, 2002) in R (R Core Development Team, 2009) and cross-validated 105 through leave-one-out cross validation (LOOCV).

106 Although there have been recent criticisms of the use of LDA in morphometric studies,

107 discussions have mostly centered on ordination, visualization of selection gradients, and

108 problems associated with a high number of variables in geometric morphometrics (Mitteroecker

109 and Bookstein, 2011). Since we use LDA in our study for supervised classification, and since we

110 did not use geometric morphometrics but rather traditional measurements, these issues are not

111 pertinent.

112

\section{Results}

114

115 LOOCV of LDA on the cranial dataset shows a high percentage of class prediction (94.1\%),

116 while that for the mandibular dataset is lower (63.5\%). The first three linear discriminants (LD)

117 from the cranial dataset account for $72.3 \%$ of the discrimination (LD1, 50.3\%; LD2, 13.3\%; LD3,

$1187.66 \%$ ) and the first eight LDs are required to explain $90 \%$ of the between-group variance. For

119 the mandibular dataset the first three LDs only account for $58.7 \%$ of the between-group variance

120 (LD1, 31.0\%; LD2, 17.1\%; LD3, 10.7\%) and eight LDs are required to capture 90\% of the

121 between-group variance. 
122 Using discriminant functions from the cranial dataset, both Peruvian cats were classified as

123 Panthera onca with posterior probabilities of $\sim 1$. Prediction accuracy is lower in the mandibular

124 dataset, though discriminant functions also classified both specimens as $P$. onca with posterior

125 probabilities of 0.998 for the 'anomalous Jaguar' and 0.961 for the 'Peruvian tiger'. The

126 predicted positions of the specimens within the LDA-ordinated space for cranial morphometrics

127 are closest to P. onca and P. pardus (Figs 3-5).

128 A scatterplot of LD1 and LD2 for large bodied cats (Neofelis, Panthera and Puma) shows the

129 two specimens overlapping with P. pardus (Fig. 3), but a scatterplot of LD1 and LD3 (Fig. 4)

130 shows them plotting closer to $P$. onca. On the other hand, a scatterplot of LD2 and LD3 (Fig. 5)

131 shows them plotting separately from P. onca and P. pardus.

132 Features consistent with identification of both skulls as those of jaguars include the concave

133 dorsal profile of the nasals, strongly concave lateral surface of the dorsal process of the maxilla

134 (Fig. 6), robust dentition, robust rostrum and relatively broad coronoid process. The two Peruvian

135 specimens exhibit a number of features typical of Panthera including pronounced nuchal and

136 sagittal crests, a short postorbital process and a relatively narrow postorbital constriction

137 (Herrington, 1986). They also possess additional features typical of all Panthera species

138 excepting the snow leopard $P$. uncia such as a relatively elongate skull, relatively prominent

139 ridges/grooves on the palatal surface posterior to the incisive foramina, and a long palate.

140 In view of the superficial similarity with $P$. tigris, note that the 'Peruvian tiger' skull can be

141 distinguished from P. tigris based on smaller adult size (the sutures are still visible but almost

142 fused), a less arched skull profile (the face of the tiger is more downturned), a relatively shorter

143 facial length, and relatively shorter nasals.

145 Discussion 
147 Our morphometric analysis confirms that both skulls can be identified as those of Jaguar P. onca.

148 Regarding the robustness of our results, lower accuracy of classification of the discriminant

149 functions in the mandibular dataset could be the result of one of two possibilities. Firstly, within-

150 group variance may be high in the mandibular dataset since mandibular morphology may be

151 variable within species. Secondly, the small number (i.e., 13) and/or choice of mandibular

152 variables may not capture species-specific morphology as well as the cranial dataset. Regardless,

153 the fact that the discriminant functions from both datasets consistently assign the Peruvian

154 specimens to Panthera onca with high posterior probabilities places confidence in this

155 assignment.

156 Despite confident assignment to $P$. onca, the Peruvian specimens are somewhat

157 morphometrically anomalous, plotting at the periphery of jaguar morphospace in the first three

158 dimensions of LD. However, since at least eight LD axes are necessary to account for $90 \%$ of the

159 between-group discrimination, the Peruvian specimens probably only ally with $P$. onca when a

160 high number of, or all, discriminant functions are taken together, not just the first three.

161 These results are consistent with the presence of jaguar characters in both specimens,

162 including a concave dorsolateral region on the maxilla and robust rostrum. Ideally, we would

163 corroborate our results with information from postcranial elements and DNA. We urge other

164 researchers collecting 'mystery' mammal remains to encourage sources to retain and donate soft

165 tissue samples. If the aberrant coat colours and patterns reported for both cats are accurate

166 (Hocking, 1992, 1996), we assume that both individuals were anomalous. Tiger-like stripes and

167 leopard-like solid spots are not typical for P. onca, but similar mutations have been reported

168 anecdotally in jaguar populations elsewhere.

169 In conclusion, our morphometric analyses indicate that the Peruvian skulls do not represent

170 potential new species. In the case of the 'Peruvian tiger', the possibility remains that a jaguar

171 skull was provided in place of the original, however. Should additional cranial material 
172 purportedly belonging to mystery big cats be discovered, morphometric techniques such as those

173 employed here should allow their identities to be determined.

\section{Acknowledgements}

176

177 We thank Ross Barnett, Anthony Giordano and Matt Bille for discussion, Barry Marsh

178 (University of Southampton, UK) for photography, Norman McLeod and an anonymous reviewer

179 for helpful comments and criticisms which improved the manuscript, and the PeerJ team for

180 editorial assistance.

\section{References}

Beckman M. 2005. Biologists find new species of African monkey (Lophocebus kipunji). Science 308: 1103.

186 Bille M. 1997. News and comment. Exotic Zoology 4 (2): 4.

187 Ceballos G, Ehrlich PR. 2009. Discoveries of new mammal species and their implications for

188 conservation and ecosystem services. Proceedings of the National Academy of Sciences 106:

$189 \quad 3841-3846$.

190 Cozzuol MA, Clozato CL, Holanda EC, Rodrigues FHG, Nienow S, de Thoisy B, Redondo RAF,

191 Santos FR. 2013. A new species of tapir from the Amazon. Journal of Mammalogy 94: 13311921345.

193 Do Tuoc, Vu Van Dung, Dawson S, Arctander P, MacKinnon J. 1994. [Introduction of a new

194 large mammal species in Vietnam]. Hanoi: Forest Inventory and Planning Institute. (In

195 Vietnamese.)

196 Duarte MB, Jorge W. 1996. Chromosomal polymorphism in several populations of deer (genus

197 Mazama) from Brazil. Archivos de Zootecnia 45: 281-287.

198 Flannery TF, Boeadi, Szalay A. 1995. A new tree-kangaroo (Dendrolagus: Marsupialia) from

199 Irian Jaya, Indonesia, with notes on ethnography and the evolution of tree-kangaroos. 
Mammalia 59: 65-84.

201 Gongora J, Taber A, Keuroghlian A, Altrichter M, Bodmer RE, Major P, Moran C, Damayanti CS, González S. 2007. Re-examining the evidence for a 'new' peccary species, 'Pecari maximus', from the Brazilian Amazon. Suiform Soundings 7 (2): 19-26.

Geissmann T, Ngwe Lwin, Saw Soe Aung, Thet Naing Aung, Zin Myo Aung, Tomy Htin Hla, Grindley M, Momberg F. 2010. A new species of snub-nosed monkey, Genus Rhinopithecus Milne-Edwards, 1872 (Primates, Colobinae), from northern Kachin State, northeastern Myanmar. American Journal of Primatology doi:10.1002/ajp.20894

Herrington SJ. 1986. Phylogenetic relationships of the Wild Ccats of the World. Kansas: University of Kansas.

Hocking PJ. 1992. Large Peruvian mammals unknown to zoology. Cryptozoology 11: 38-50.

Hocking PJ. 1996 (for 1993). Further investigations into unknown Peruvian mammals. Cryptozoology 12: 50-57.

Jones T, Ehardt CL, Butynski TM, Davenport TRB, Mpunga NE, Machaga SJ, De Luca DW. 2005. The Highland mangabey Lophocebus kipunji: a new species of African monkey. Science 308: 1161-1164.

Mitteroecker, P. and Bookstein, F, 2011. Linear discrimination, ordination, and the visualization of selection gradients in modern morphometrics Evolutionary Biology 38: 100-114.

Mosimann JE. 1970. Size allometry : size and shape variables with characterizations of lognormal and generalized gamma distributions. Journal of the American Statistical Association 65: 930-945.

R Core Development Team 2009. R: A Language and Environment for Statistical Computing. In, 2.10.1 ed. Vienna, Austria: R Foundation for Statistical Computing.

Reeder DM, Helgen KM, Wilson DE. 2007. Global trends and biases in new mammal species discoveries. Occasional Papers, Museum of Texas Tech University 269: 1-35.

Sakamoto, M., Ruta, M. 2012. Convergence and divergence in the evolution of cat skulls: temporal and spatial patterns of morphological diversity. PLoS ONE 7: e39752. doi:10.1371/journal.pone.0039752

Shuker KPN. 1989. Mystery Cats of the World. London: Robert Hale.

Van Dung V, Giao PM, Chinh NN, Tuoc D, Arctander P, MacKinnon J. 1993. A new species of living bovid from Vietnam. Nature 363: 443-445.

van Roosmalen MGM, Frenz L, van Hooft P, de Iongh HH, Leirs H. 2007. A new species of living peccary (Mammalia: Tayassuidae) from the Brazilian Amazon. Bonner zoologische 
Beiträge 55: 105-112.

234 Venables WN, Ripley BD. 2002. Modern applied statistics with S, Fourth edition. New York: 235 Springer. 495 p.

236 Werdelin L, Yamaguchi N, Johnson WE, O’Brien SJ. 2010. Phylogeny and evolution of cats 237 (Felidae). In Biology and conservation of wild felids: 59-82. Macdonald, D.W. \& Loveridge, 238 A.J. (Eds) Oxford: Oxford University Press.

FIGURE CAPTIONS

242 Figure 1. 'Peruvian tiger' skull, replica of original (CF-0023. Original $=$ MHN 8736). Specimen shown in (A) left lateral view, (B) dorsal view and (C) ventral view.

Figure 2. 'Anomalous jaguar' skull, replica of original (CF-0022. Original = MHN 9397).

Specimen shown in (A) left lateral view, (B) dorsal view and (C) ventral view.

Figure 3. Scatterplot showing relative positions of Peruvian specimens relative to other large felids. This scatterplot depicts the first two linear discriminant axes. These results show both

Peruvian specimens to be close to $P$. onca, but overlapping predominantly with $P$. pardus.

252 Figure 4. Scatterplot showing relative positions of Peruvian specimens relative to other large felids. This scatterplot depicts the first and third linear discriminant axes. Here, the two Peruvian specimens are especially close to $P$. onca.

Figure 5. Scatterplot showing relative positions of Peruvian specimens relative to other large felids. This scatterplot depicts the second and third linear discriminant axes. In contrast to Figs 5 and 6, these results show the two Peruvian specimens plotting separately from both $P$. onca and P. pardus. As explained in the text, a close relationship with $P$. onca specimens, however, is well supported by morphological characters.

262 Figure 6. Dorsolateral views of the two Peruvian cat skulls to show jaguar-like characters present 263 in the snout region. In both specimens, the rostrum and dentition is proportionally robust, the 
264 nasals are dorsally convex, and the dorsolateral region of the maxilla is strongly concave. (A)

265 ‘Anomalous jaguar' skull, replica of original (CF-0022. Original = MHN 9397). (B) 'Peruvian

266 tiger' skull, replica of original (CF-0023. Original $=\mathrm{MHN} 8736)$. 


\section{Figure 1}

'Peruvian tiger' skull

Figure 1. 'Peruvian tiger' skull, replica of original (CF-0023. Original $=$ MHN 8736). Specimen shown in $(A)$ left lateral view, $(B)$ dorsal view and $(C)$ ventral view.

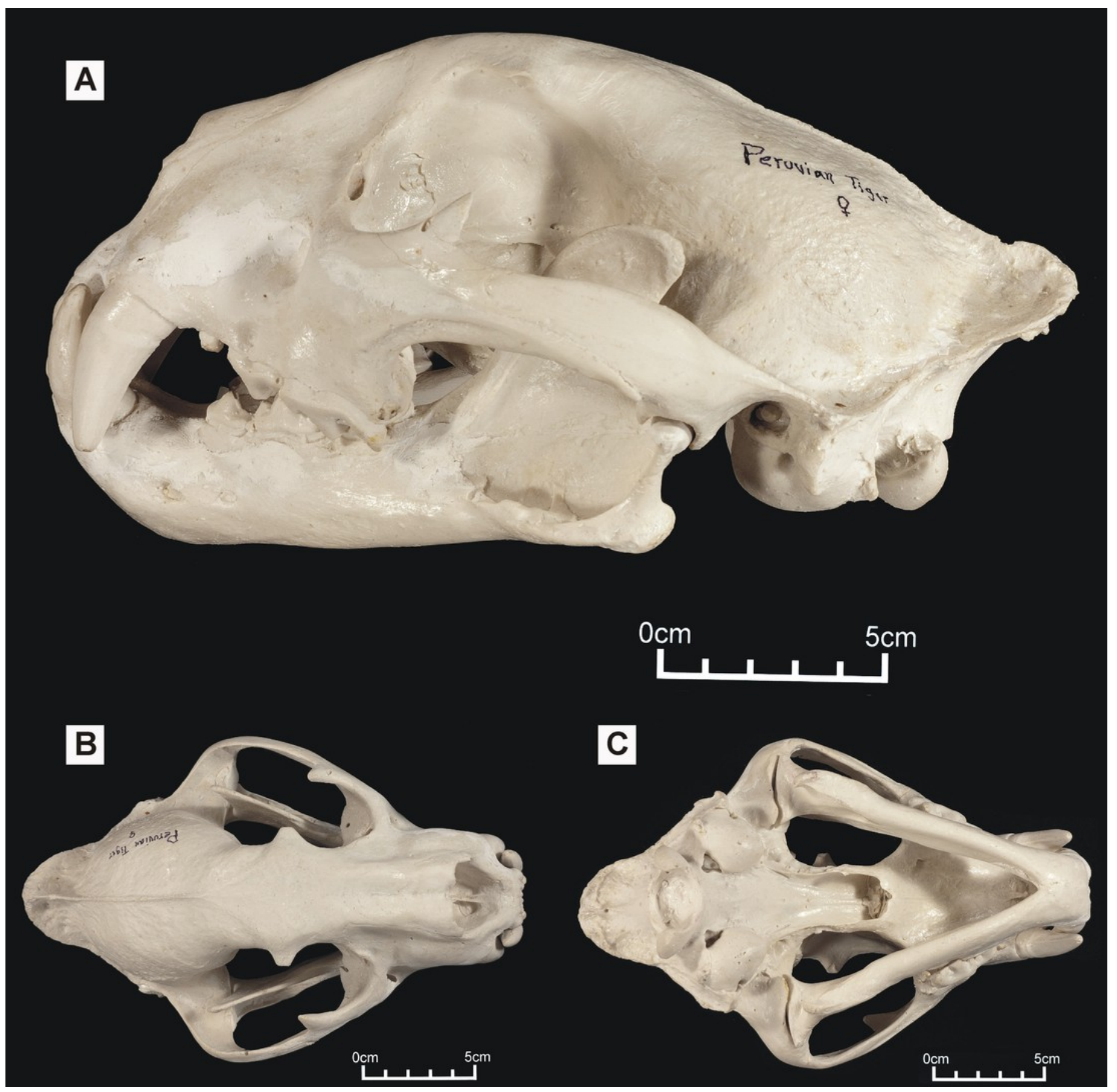




\section{Figure 2}

‘Anomalous jaguar' skull

Figure 2. 'Anomalous jaguar' skull, replica of original (CF-0022. Original = MHN 9397).

Specimen shown in $(A)$ left lateral view, $(B)$ dorsal view and $(C)$ ventral view.

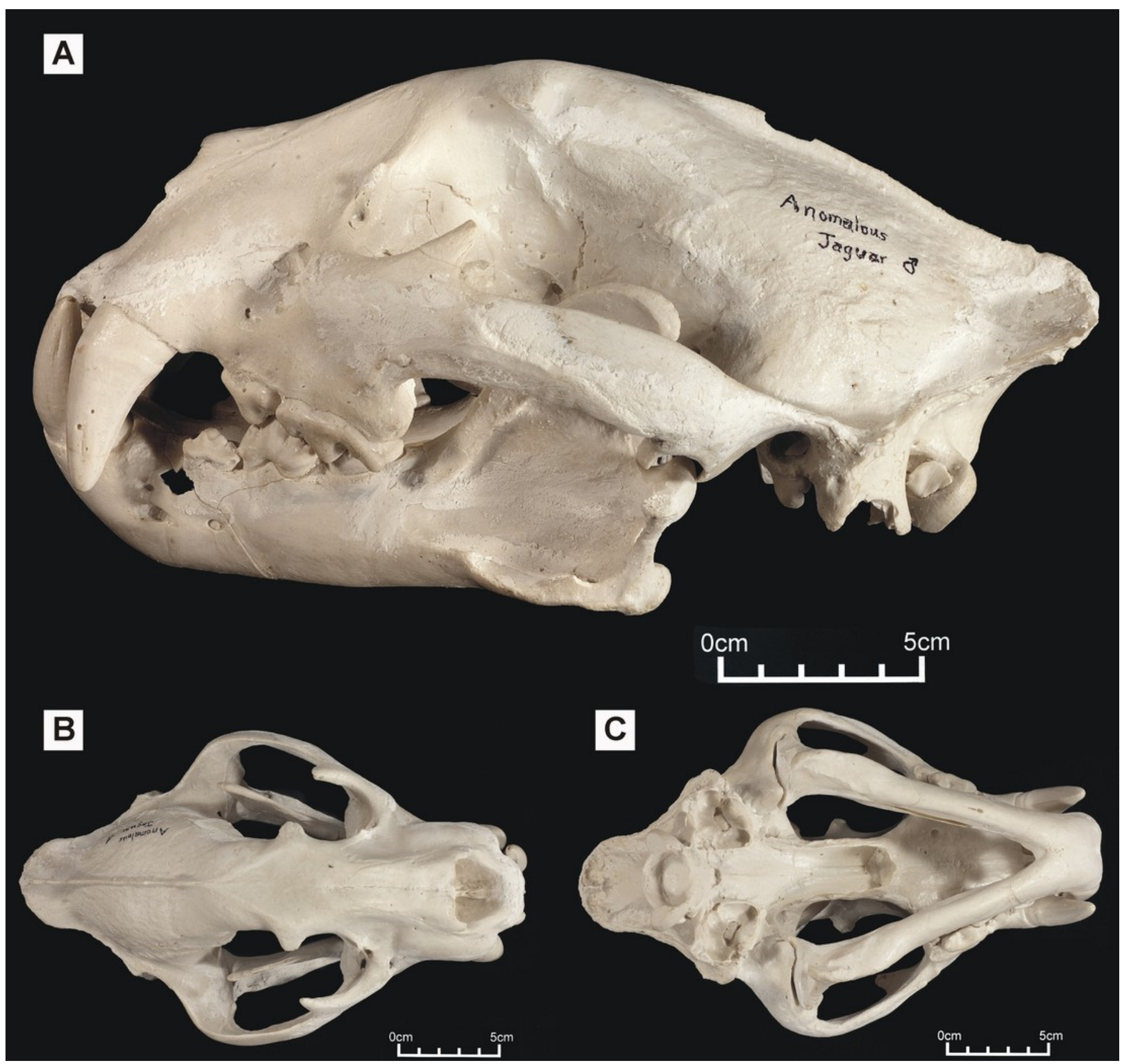




\section{Figure 3}

Scatterplot showing relative positions of Peruvian specimens relative to other large felids

Figure 3. Scatterplot showing relative positions of Peruvian specimens relative to other large felids. This scatterplot depicts the first two linear discriminant axes. These results show both Peruvian specimens to be close to $P$. onca, but overlapping predominantly with $P$. pardus.

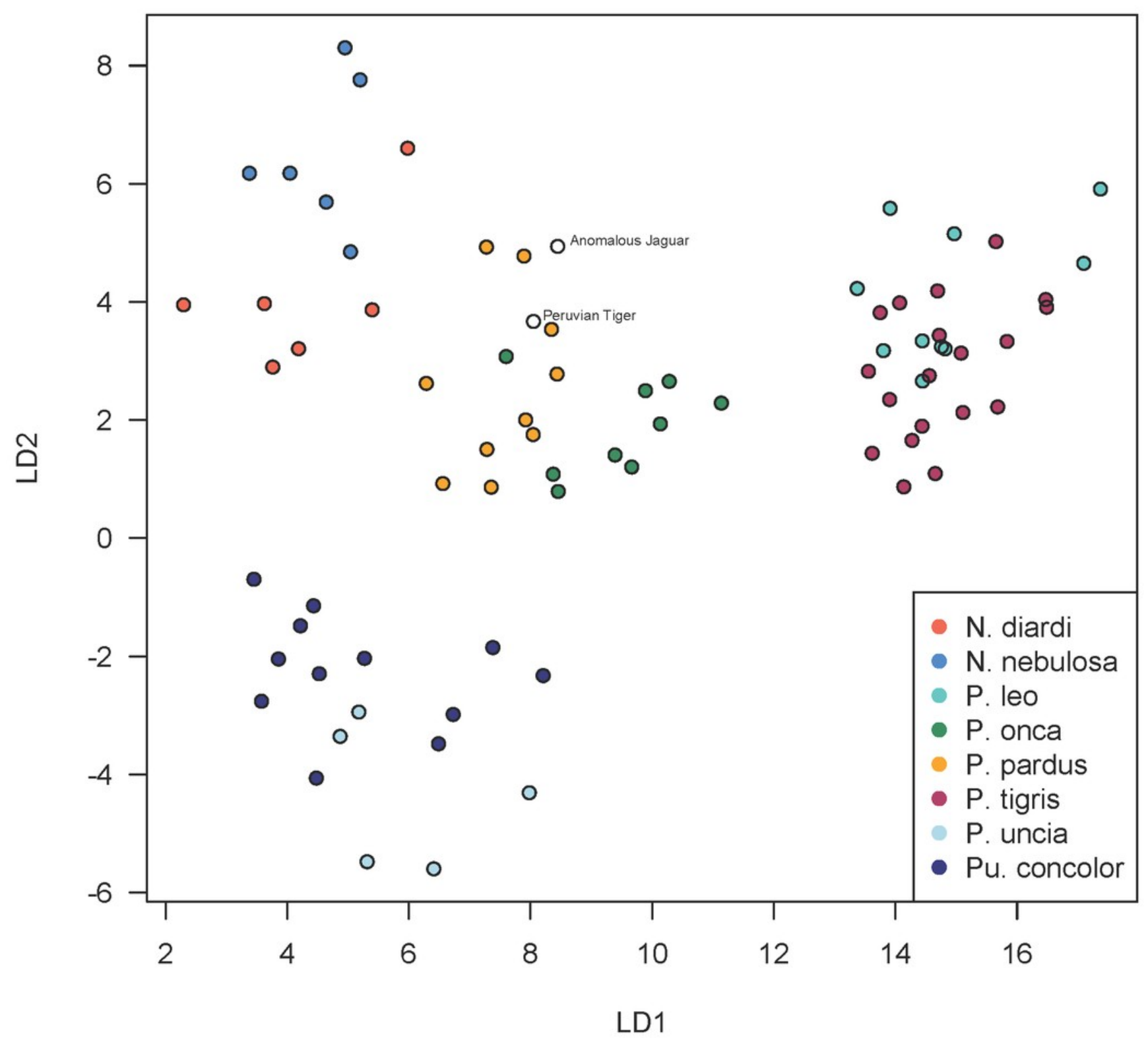




\section{Figure 4}

Scatterplot showing relative positions of Peruvian specimens relative to other large felids

Figure 4. Scatterplot showing relative positions of Peruvian specimens relative to other large felids. This scatterplot depicts the first and third linear discriminant axes. Here, the two Peruvian specimens are especially close to $P$. onca.

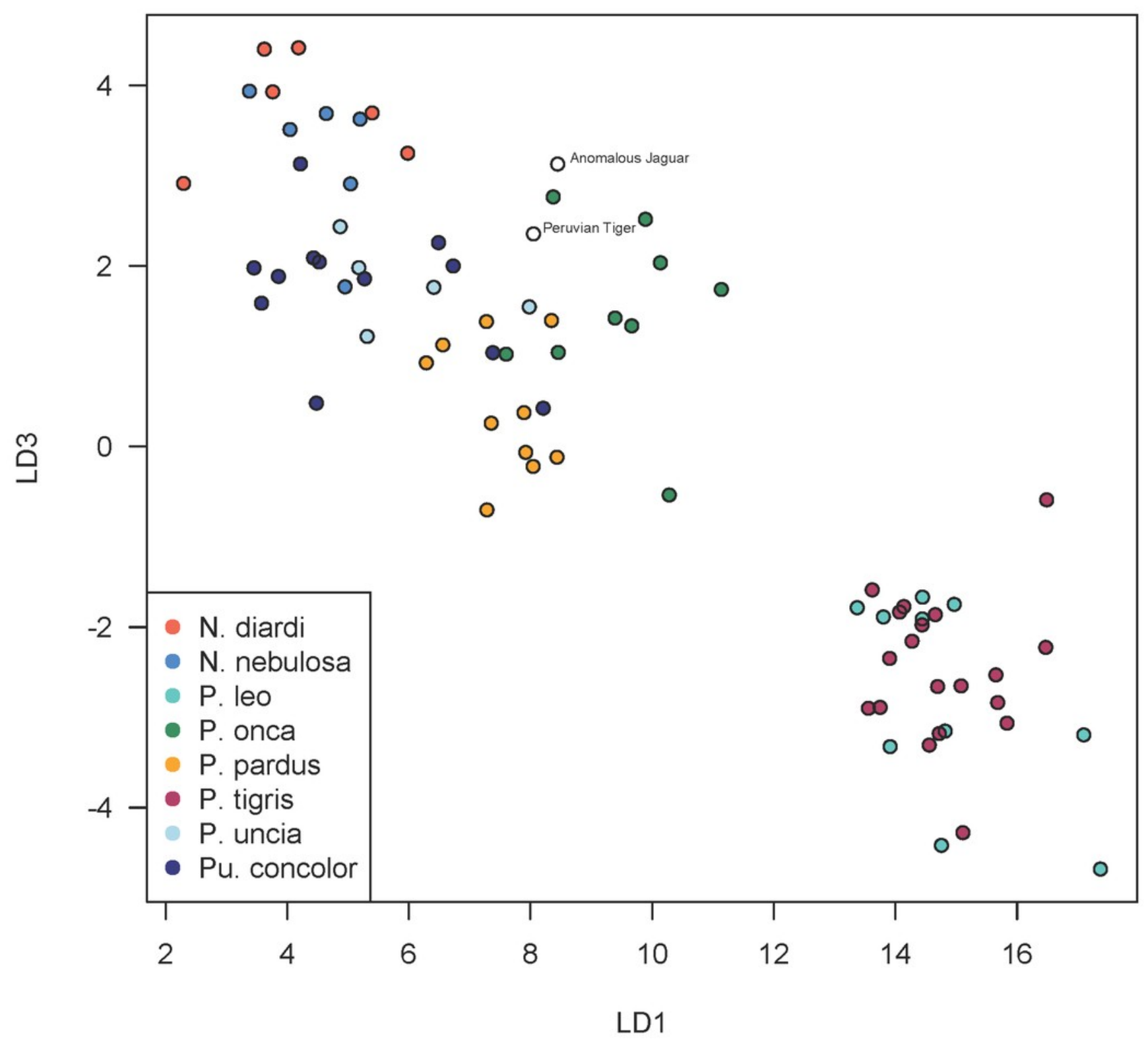




\section{Figure 5}

Scatterplot showing relative positions of Peruvian specimens relative to other large felids

Figure 5. Scatterplot showing relative positions of Peruvian specimens relative to other large felids. This scatterplot depicts the second and third linear discriminant axes. In contrast to Figs 5 and 6 , these results show the two Peruvian specimens plotting separately from both $P$. onca and $P$. pardus. As explained in the text, a close relationship with $P$. onca specimens, however, is well supported by morphological characters. 


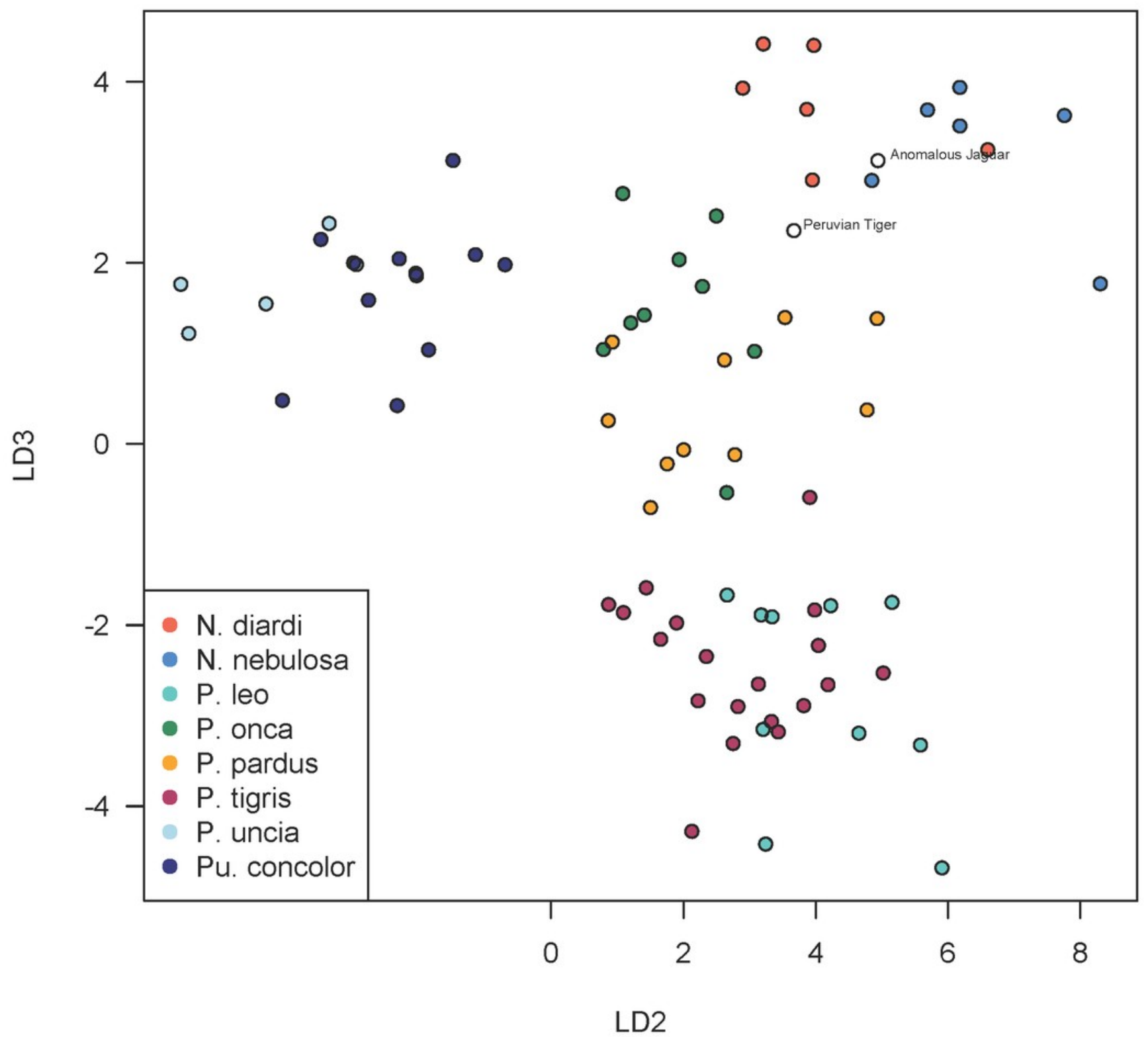




\section{Figure 6}

Dorsolateral views of the two Peruvian cat skulls to show jaguar-like characters present in the snout region

Figure 6. Dorsolateral views of the two Peruvian cat skulls to show jaguar-like characters present in the snout region. In both specimens, the rostrum and dentition is proportionally robust, the nasals are dorsally convex, and the dorsolateral region of the maxilla is strongly concave. (A) 'Anomalous jaguar' skull, replica of original (CF-0022. Original = MHN 9397). (B) 'Peruvian tiger' skull, replica of original (CF-0023. Original = MHN 8736).

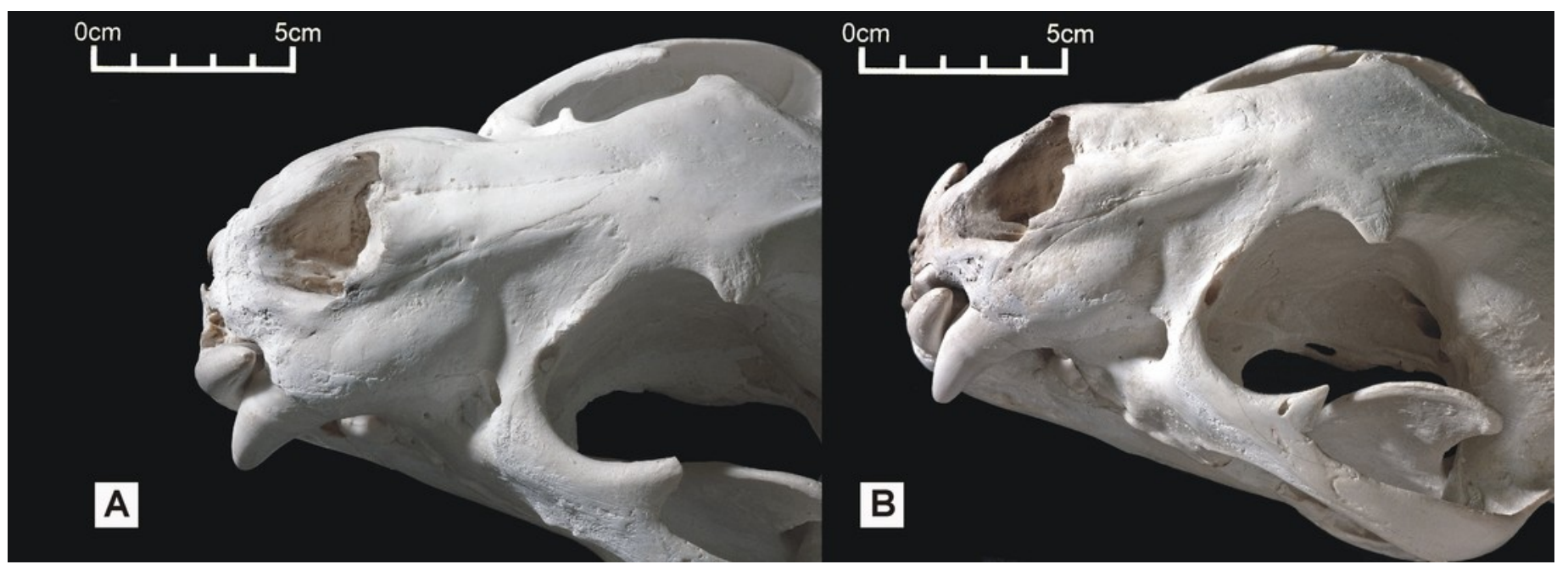

